\title{
Continuing medical and dental education on the global stage: the nexus of supporting international Christian healthcare workers and developing educators
}

\author{
Lyubov D Slashcheva ${ }^{a}$, Mark A Strand ${ }^{b}$, Ruth E VanReken ${ }^{c}$, Collin Sanford ${ }^{d}$, J \\ Dwight Phillips ${ }^{e}$, Gloria Halverson ${ }^{\dagger}$ \\ ${ }^{a}$ DDS, Resident/Fellow, University of lowa Department of Preventive and Community Dentistry, Iowa, USA \\ ${ }^{b}$ Phd, MPH, Professor, College of Pharmacy and Department of Public Health, North Dakota State University \\ ${ }^{\mathrm{C}} \mathrm{BSN}, \mathrm{Co}-$ Founder, Families in Global Transition \\ ${ }^{\mathrm{d} D M D}$, Professor Emeritus, University of Connecticut School of Dental Medicine, Farmington, CT \\ ${ }^{\mathrm{e}} \mathrm{MD}, \mathrm{MPH}$, Professor of Pediatrics, Mayo Clinic, 200 First Street SW, Rochester, MN \\ ${ }^{\mathrm{f}} \mathrm{MD}$, Professor Emeritus, Medical College of Wisconsin, Madison, WI
}

\begin{abstract}
One of the challenges facing international healthcare missionaries is that of maintaining up-to-date knowledge and staying current with professional certification. Since 1978, annual programs by the Christian Medical and Dental Associations have offered professional continuing education to thousands of US healthcare professionals serving as missionaries in the regions of Africa, Asia, and, in more recent years, globally. In addition, conference programming is designed to prepare, train, and support healthcare missionaries to, in turn, serve as educators in their places of ministry. The program is designed for both professional education and personal encouragement. Utilizing historical documents from program facilitation and interviews from those involved with its implementation, this paper describes the history, vision, and favorable quantitative growth and qualitative impact on participants. The program continues to grow as healthcare missionaries are educated near their places of service, while reinforcing their own roles as educators.
\end{abstract}

Medical missions as a catalyst in global health

Healthcare missions have a long history and have been closely linked with the development of modern medicine. Medical missions began with the Catholic orders in the $14^{\text {th }}$ century. Protestant missions began with Dr. John Thomas in India in
1773. ${ }^{1}$ Throughout the $19^{\text {th }}$ century, the number of missionary doctors on the field reached an initial peak of 1,125 in 1925 , not counting the number of nurses and ancillary medical workers. ${ }^{2}$ Medical missionaries helped to establish modern medicine in many countries of the developing world. 3,4 Yet, despite the historical role that Christian expressions of mission have played, ${ }^{1}$ reports of the scale and

Nov 2016. Christian Journal for Global Health, 3(2): 27-37. 
impact of medical missions often goes unnoticed in wider global health circles. ${ }^{3,5,6}$ This paper sets out to describe one aspect of healthcare missions globally that is the shared foundation of all healthcare missionaries: the need to engage in evidencebased learning, maintain current knowledge, and employ standard practices in healthcare. One contribution to this foundation is the role of a professional continuing education program of the Christian Medical and Dental Associations to provide educational opportunities for US healthcare missionaries working around the world.

The term, healthcare missionaries, in this paper, refers to healthcare professionals who have devoted themselves to long-term, cross-cultural, missionary service through clinical work under the auspices of a Christian missionary organization. Synonymous terms used to refer to the population served by the program described in this report include healthcare missionary, those engaged in missionary service, missionary physicians, and international healthcare workers. Those who are eligible for professional continuing education credits at these meetings include physicians, dentists, physician assistants, nurse practitioners, nurses and pharmacists. The authors estimate that worldwide there are approximately 1000 missionary physicians serving cross-culturally for $\geq 2$ years, and another 1000 individuals serving in other health professions. Less than $50 \%$ of these individuals work in mission hospitals; the others work in government hospitals, community offices, or other settings depending on regional accessibility of faithbased organizations. Hence, the historical stereotype of a solo missionary doctor who provides all the medical care for a large population of extremely needy people is no longer the norm. Most of these international healthcare professionals work for organizations where healthcare is only one aspect of many areas of service, and these organizations may not be prepared to provide strategic and healthcarespecific leadership or training. This contributes to frustration among these workers. ${ }^{7,8}$
The professional continuing education program described in this report exists to provide cutting-edge medical, surgical, dental, and community health education to these long-term healthcare missionaries to improve their skills and to maintain their licensure and has been able to fill the gaps in support of educational and professional development by providing education, resourcing, and encouragement to international healthcare workers who are then able to more effectively carry out their work and serve as educators themselves within each diverse ministry setting. The program relies on the commitment of volunteer healthcare educators from reputable academic institutions to attend conferences as faculty to teach on current medical knowledge and practices. This faculty also has experience working in low resource countries, an asset that improves the practical application of didactic concepts to the practice settings of conference participants. A natural process of mentoring has been established, creating lifelong friendships with professional colleagues across the world.

Since its inception and through current years, the program has also provided a source of professional and spiritual support to these missionaries, helping to connect their work to modern standards of global health. ${ }^{9}$ Healthcare missionaries are vulnerable to mental health challenges. ${ }^{10,11}$ Missionary doctors are the "poorest and most isolated of [their] profession."12 Traumatic experiences, including natural disasters, warfare, terrorism, and epidemics, are experienced frequently by healthcare missionaries. They also experience significant levels of anxiety associated with occupational issues, acculturation, and physical illness. ${ }^{13,} 14$ Isolation and added administrative and leadership responsibilities are also contributing factors to stress. ${ }^{15,16,17}$ The program described has proven to be a safe setting in which healthcare missionaries could receive succor and counsel within a safe community of likeminded individuals, thus helping them to remain in their 
field of service beyond what they might have in the absence of such programming. ${ }^{18}$

The Christian Medical and Dental Associations serves a membership of nearly 18,000 Christian healthcare professionals through more than 40 programs and services with the mission to "change hearts in healthcare." 19 Recognizing the above-mentioned opportunities nearly 40 years ago, the CMDA embarked on an endeavor that continues to respond to the genuine needs of healthcare missionaries through the following aims: 1) supporting, educating, and resourcing international healthcare workers, and 2) developing effective international healthcare educators. The establishment, evolution, and impact to date of these two program aims are described in this paper.

\section{History and framework of CMDA's professional continuing education program}

In 1976, the Christian Medical and Dental Association began the process of developing a continuing educational program for healthcare workers serving in overseas settings where they had limited access to professional continuing education. This led to the first CMDA-sponsored professional continuing education conference for cross-cultural healthcare workers. The first conference held in Liberia, in January 1978, had two goals. The first was to send short-term healthcare workers in to replace long-term workers to give them a short time of respite. The second goal was to provide the longterm workers medical education on current healthcare topics through the conference program. The first conference in Liberia required substantial flexibility and much onsite coordination, both of which encouraged facilitators to focus on the overarching role of supporting the participants and their families. Such emphasis on holistic programming still presides as a foundation for all program activities, demonstrated by the formation of special spouse and child programs, as well as focused times of fellowship for whole family units to engage with one another in encouraging ways. These components emerged and remain nearly as central to the program as its educational focus. Providing short-term replacement clinicians as relief for participants of the program proved difficult to coordinate and was discontinued after the first year of the conference as many participants became able to independently negotiate leave time and local relief from their settings of work.

In 1979, the ad hoc committee that facilitated the first conference was formalized into a Commission dedicated to education of international healthcare workers on behalf of the CMDA. The second conference was held in Kenya, in March 1980, and a third followed in 1982, also in Kenya. The first conference held in Asia (Malaysia) was held in 1983. Thereafter, these conferences have been held on a yearly basis, alternating between Africa and Asia (with the exception of 2008 when turmoil in Kenya prevented the conference from proceeding). The Asia conference has usually been held in Thailand. Since 2014, the conference routinely held in Africa has been held in Europe in a larger venue which has accommodated more participants in recent years and has welcomed a global audience of participants serving in any country. Table 1 shows the guiding principles for the Commission: two aims of the program focus on education and encouragement of international healthcare workers with the vision statement centered on the well-being of these individuals; spanning the two aims, core values are informed by scripture and give direction to the Commission. 


\begin{tabular}{|c|c|}
\hline \multicolumn{2}{|c|}{ Mission: } \\
\hline \multicolumn{2}{|c|}{$\begin{array}{c}\text { To advance God's kingdom by providing accredited education and spiritual encouragement } \\
\text { to North American Christian healthcare professionals who serve overseas. }\end{array}$} \\
\hline \multicolumn{2}{|c|}{ Vision Statement: } \\
\hline \multicolumn{2}{|c|}{ Healthcare missionaries thriving in their professional, spiritual, and personal lives. } \\
\hline \multicolumn{2}{|c|}{ Core Values: } \\
\hline $\begin{array}{l}\text { Spiritual Values: } \\
\text { Guided by Scripture (II Timothy 3:16-17) } \\
\text { Guided by the Holy Spirit (John 14:26) } \\
\text { Guided through Prayer (Psalm 88:13) }\end{array}$ & $\begin{array}{l}\text { Professional Values-To Maintain: } \\
\text { Character (Psalm 37:30) } \\
\text { Compassion (Zechariah 7:9) } \\
\text { Competence (Proverbs 18:15) }\end{array}$ \\
\hline
\end{tabular}

The success of this professional continuing education program is related to the commitment and quality of the Commission members. A minimum of 18 members, usually serving 3 consecutive 2year terms, actualize the purposes stated in Table 1 within a defined leadership and governance structure, annually reporting on activities directly to the CMDA Board of Trustees. The Commission is composed of highly qualified healthcare professionals from universities and medical centers around the world (though the majority represents the United States). In addition to being encouraged to financially support the program and contribute as faculty, Commission members are central to the planning and implementation of the program, including recruitment of in-kind faculty contributors, processing registrations for participants, facilitating accreditation of program content as an independent CME accrediting agency, and ensuring appropriate venue accommodations. As such, members of the Commission have been integral to the advancement of international healthcare pedagogy, support and encouragement of international healthcare workers, and development of a strong cohort and pipeline of international healthcare educators.

This paper utilizes minutes from Commission meetings, reports to the CMDA Board of Trustees, and interviews of Commission members to describe emerging positive impact resulting from the program.

\section{Quantitative impact}

The professional education program described currently consists of four specialization tracks: Medicine, Surgery, Community Health, and Dentistry. Leaders of these tracks with expertise in their field are responsible for establishing the teaching program and recruiting faculty to present sessions at the conference within their track. There are some general sessions on common crossdisciplinary topics, but most conference periods include concurrent teaching sessions in each track.

Total participation (Figure 1) has increased over time. Please note that in Figure 1 the bolded green line represents total participants and reflects trends from the y-axis scale to the right of the graph, while the y-axis scale to the left of the graph represents trends by specific categories of participants. Though each venue has historically welcomed a majority of participants from either Africa or Asia, both conferences have been open to all countries since 2014 and have included those serving in Europe, South America, and beyond. Since the conference venue in Europe accommodates more participants from a global range, it will be described as the Africa/Global 
conference while the other conference that still attracts those serving primarily in Asia will be referred to as the Asia conference. Appreciable changes in participation occurred at the turn of the century for the Asia conference (an increase from $\sim 160$ to $\sim 570$ of total participants, as shown in Figure 1A) and for the Africa/Global conferences after 2010 (an increase from $\sim 300$ to $\sim 700$ of total participants, as shown in Figure 1B). Tracking of participation data has not been uniform throughout 40 years of program facilitation, particularly in the reporting of nurses and other providers (ex: physician assistants, nurse practitioners, midwives, non-MD physicians, physical/occupational therapists, pharmacists, PhDs). Dentist participation has remained level at 15-30 participants each year. Since 2014, the conference held in Africa was offered in Europe, where a larger venue accommodated more participants; this aligns with the marked increase in participation in the Africa/Global conference since 2014 and may account for the slight decline in participation volume in the latter years of conferences held in Asia.

Figure 1: Conference Participation (Note that the y-axis for total participation is to the right of each graph in green)

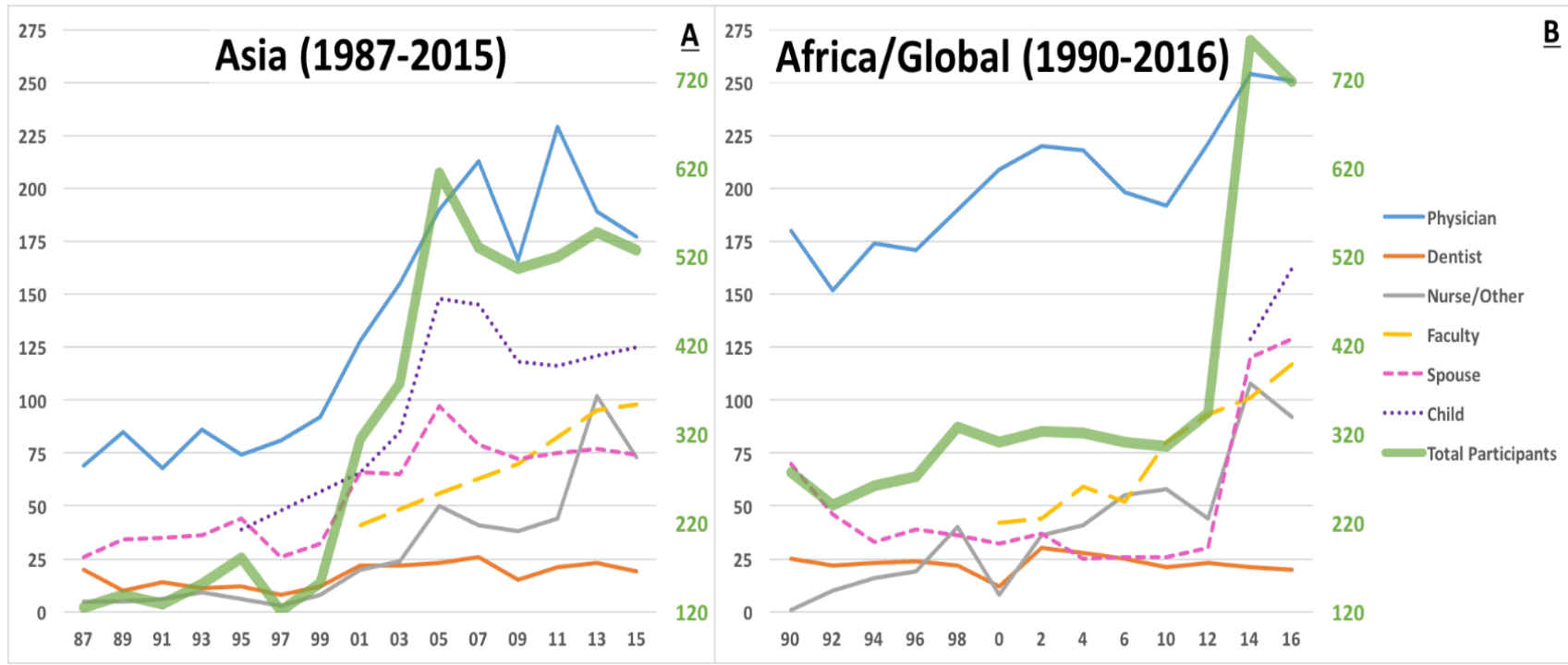

International healthcare workers who participate in the conferences serve in approximately 30 to 60 different countries (Figure 2). Representation in excess of 75 countries was seen during the first conference held in Europe rather than on the continent of Africa since the size of the new venue allowed organizers to allow healthcare workers to participate regardless of where they were serving.

Acquired continuing education (Figure 3) approximates 10,000 hours per conference across all participants, with the exception of 2012 and 2015 when claimed continuing education hours are nearly a third lower. The number of faculty participants has nearly doubled in the last decade (Figure 1). 


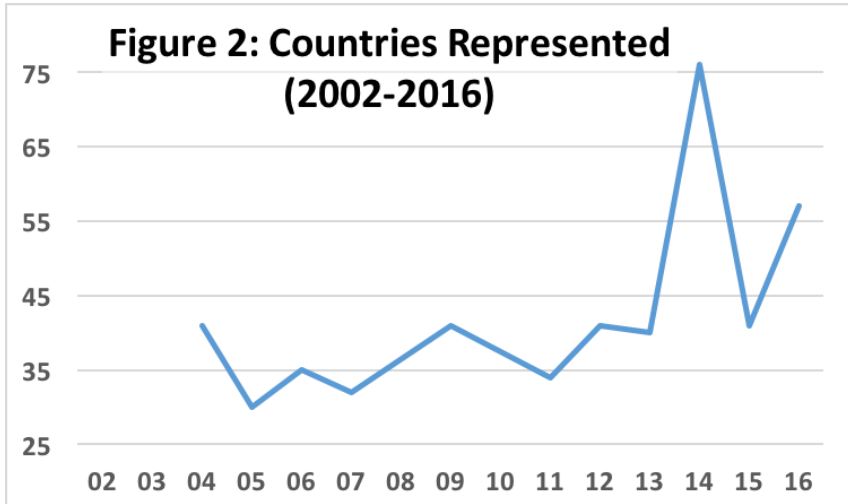

The continuing education program of CMDA has offered at least some life support training since its inception (Figure 4), tailoring the diversity and sophistication of certification to participant demand, accredited course director availability, and trends in US training requirements. These courses have

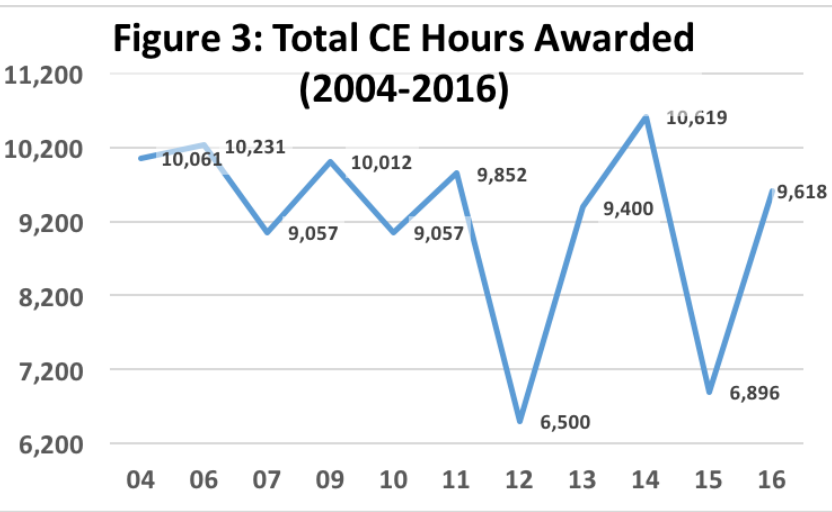

included the following: BLS=Basic Life Support; ACLS=Advanced Cardiac Life Support; PALS= Pediatric Advanced Life Support; $\mathrm{HBB}=$ Helping Babies Breathe; ALSO=Advanced Life Support Obstetrics; NRP=Neonatal Resuscitation Program.

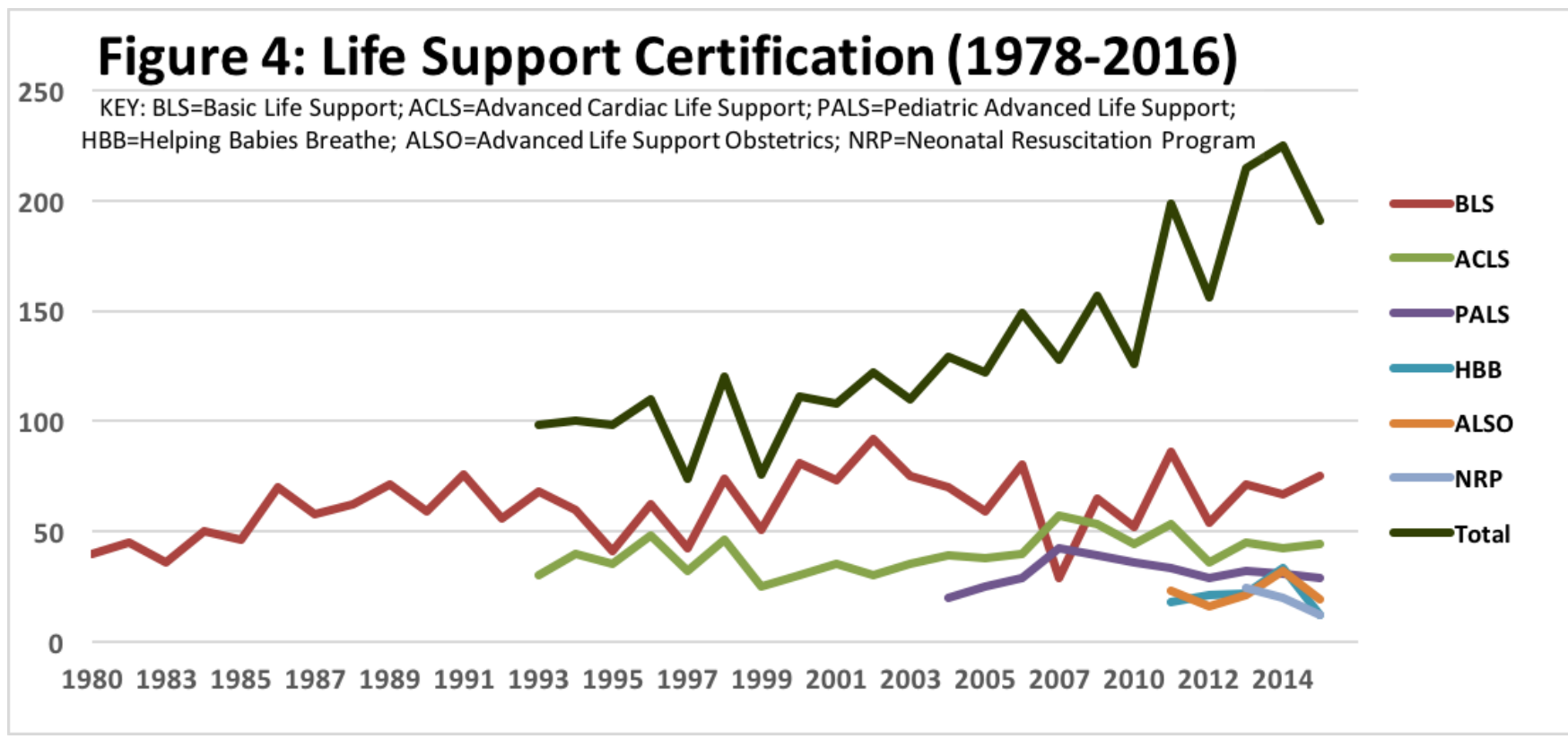

Besides continuing education and other training sessions, spouse/child programs, spiritual programming, and overall times for fellowship and interaction, Research Symposia have been added as a way for participants to share case reports, innovation, and original research from their settings. With 5 posters presented in 2015 and 18 posters (all related to an indigenous surgical training program) presented in 2016, this initiative will likely continue to grow, adding another educational perspective and opportunity for information sharing and collaboration among participants. 


\section{Qualitative impact}

In addition to quantitative results about the magnitude of international healthcare workers educated and hours of educational credit provided, there have also been significantly favorable qualitative outcomes from the annual conferences. The qualitative impact of this program may be best demonstrated by participants who express their gratitude for the unique offerings of the program:

I have finally found a conference with "my" people; people who understand me and my needs. Since attending this conference I am better equipped to serve in my area of the world as well as refreshed, understood and encouraged.

I'm so grateful I came to [this conference] ( $1^{\text {st }}$ time attendee). It will radically impact my ability to stay on the field long term.

\section{Aim 1: supporting, educating, and resourcing international healthcare workers}

In offering this professional continuing education program, the CMDA has maintained a consistent understanding of mission and service by requesting feedback, utilizing surveys, and implementing research (ex: the PRISM Survey ${ }^{20,21}$ ) to ensure that the conference is in step with and truly meeting the educational and spiritual needs of healthcare missionaries. This holistic approach focuses on healthcare workers and their families, prioritizing encouragement in support of education. As in many faith-based endeavors, these conferences naturally take on a posture of fellowship, where Biblical teaching, worship and spiritual communion add value to the educational components. This context serves as spiritual support for the attendees, as many families do not have access to as large a group of fellow believers with whom to interact in their settings of work. The program has sought to be responsive to these needs with adequate family and spiritual programming but has also emphasized the need to balance these with the functional educational purposes of the conferences. With the increase of virtual opportunities to acquire continuing education credits, the in-personal appeal of the conferences has increased the value of both the educational and spiritual components in this program, despite the associated cost of attendance. Navigating these changes and needs, high-quality education has consistently been granted as the unique contribution of this program to the cause of missions.

Though the functional purpose of the program is providing accredited education, supporting international healthcare workers and their families is a parallel aim. The synergy of learning from peers during the conferences has reportedly contributed to an increased quality of life and a greater ability to persevere in their work. Specific examples of ways the program has made adjustments towards this end include changing the venue of conferences to increase affordability and accessibility, flexibility in the way participants utilize the conference space for education, mutual support, leisure, and the appropriateness of the venue for all members of the family. Special programming for non-healthcare professional female and male spouses has proven a powerful source of mutual support and encouragement. Professional counseling services are also wellutilized by participants throughout the conference. Child programming is often separated into 2-3 age cohorts and has focused on the spiritual and identity formation of the children, development of relationships with other children who are growing in cross-cultural settings, and includes time for leisure and entertainment with peers and family. All participants may join morning devotional/prayer meetings and evening worship services, during which peers present field reports on the work in which they are involved. A distinguished keynote lecture is also a highlight of each conference. This not only serves as an inspiration to those gathered, but it also provides an opportunity for networking, mentoring, and an exchange of information/ practices between areas of work. Apart from these 
formal spiritual and educational programs, informal gatherings are organized by participants between sessions or at meal times to convene according to discipline, region, sending organization, or interest (ex: Community Health Evangelism, water sanitation, etc.).

Thus, the program has been effective in supporting the daily work of long-term international healthcare workers. In addition, several long-term workers report having been on the brink of abandoning their work when they went to the conference; repeatedly, missionary careers have been saved as workers obtain encouragement to carry on. This sentiment is demonstrated by the following participant quotes:

It's not easy to describe just how much [this program] has come to mean to me as I serve long-term in Asia. The challenges in my assignment are not insignificant spiritual darkness, poverty, tropical heat, small numbers of like-minded people incountry, etc and plenty of joys and opportunities to grow, as well! But knowing every two years we will come together at [this conference] to be refreshed academically with state-of-theart medical education, to have fellowship with a like-minded peer group, and to benefit from informal mentoring with those more experienced than myself has enabled me to keep pressing on through the mountains and valleys! Really, I am not exaggerating when $I$ say [that this program] is an invaluable ministry and we thank God for those willing to go to all the huge effort to faithfully serve us. Thank you!

Early in my career, I temporarily lost my medical license in the States due to the lack of documented CME. This conference rescued me... My license [in-country] depends on an active license in the USA.

\section{Aim 2: developing effective international healthcare educators}

The consistency of high quality educational opportunities and participation, as described above, does not demonstrate the advancements in pedagogy that have taken place. A near doubling of the number of faculty participating in both the Africa/Global and Asia conferences within the past decade (Figure 1) suggests that the program is a well-established opportunity for diverse academic and clinical experts to present and develop relevancy of their content before an international forum. This stability and growth affirms the program's commitment to educational advancements in ways that do not compromise but enhance support of international healthcare workers and also allow flexibility for innovation in pedagogy. The ten-day nature of each conference allows plentiful time for faculty to interact with participants to receive feedback on specific gaps that exist in the ability to apply presented content/practices to their settings of work. These interactions inform the nature of future course offerings. The conference has routinely offered several themed tracks, including Medicine, Surgery, and Dentistry; upon additional feedback from those in community-based settings and in health administration roles, the Community Health track was added and developed with various emphases over the years - actual community health, public health, administration, leadership, cultural adaptation, healthcare ethics, and faculty development. Case-based discussions and consultations with faculty experts encouraged the formation of MD Second-Opinion, a program that engages over 230 specialty clinicians that offer 3-5 virtual clinical and educational consultations to international healthcare workers per week. A commitment to presenting contemporary standardsof-care has included hands-on training with technology that may not yet be available in the settings where participants work but maintains their competence by US measures. The variety of life support training offered (Figure 4) represents both the requirements of specialists in the developed 
world as well as skills relevant to the needs of participants in their work settings. Some program participants have been trained to be life support trainers for future programs internationally and in their places of service. A limber and committed faculty cohort has enabled quick adoption of content about high profile topics like HIV/AIDS in the 1980s and Ebola in 2015. These examples demonstrate a commitment to high-quality standards of healthcare education as well as being responsive and relevant to the workplace needs of participants. Over time, more and more conference participants have served as conference faculty, presenting lectures and leading workshops. In the New Testament model of Paul and Timothy, educators are training participants who then go on to teach others. Conference materials are available for adaptation and use in other settings. Conference participants experience models of cutting-edge education and are thus equipped to educate others in these novel ways.

In addition to evolving and adapting content, the way in which content is presented has continually progressed. Physical slide presentations and carousel-projectors were utilized very early in the program, when such technology was not yet available in low-resource settings. Initial paper binders of conference content were replaced with CD, DVD, and currently flash drive storage of all presentations for participants to reference after the conclusion of conferences. Incorporation of immediate-audience-response systems into presentations has enabled participant engagement and evaluation during sessions. Hands-on workshops in endoscopy, ultrasonography, casting, radiographic interpretation and other clinical techniques have been popular educational opportunities. Case-based discussions and break-out sessions have also been well-attended opportunities to apply and develop interpretation and diagnostic skills. These diverse teaching techniques have been valuable to both participants and faculty who seek to respond to the unique needs of international healthcare learners.
Global issues such as HIV-AIDS, mental health, human migration, disaster relief and human trafficking present opportunities for critical contributions to vulnerable populations. The world is changing, ${ }^{22}$ and the role of the healthcare missionary is also changing. ${ }^{17}$ New focuses such as medical research, residency training and systematic management of chronic diseases also have opportunities for healthcare missions to support the development of strong national health care systems in developing settings. The conferences described address these issues as they arise, thus helping increase the competence of healthcare missionaries to address such concerns that frequently present more urgently in their work settings than in North America. Healthcare is a highly close-knit global society, using highly uniform standards of diagnosis and care, so partnership and collegiality are not difficult to create. The discussed initiatives and developments are a small glimpse into the opportunities available in the current global health climate.

\section{The nexus of equipping international healthcare workers and developing international healthcare educators}

Several developments have enabled the two aims of the program described to intertwine. Healthcare workers in international settings have contributed in the leadership, planning, and faculty roles. Their engagement has enabled shrinking of the gap that often exists between educators from the developed world and international healthcare learners in low-resource settings. This pattern has also helped to build international healthcare capacity, empowering and mobilizing for peerresourcing that is most appropriately informed and relevant to unique needs in low-resource settings. In fact, there is a rise in the number of international healthcare workers whose primary appointment is to educate in indigenous settings. Engagement of national workers, such as those from the PanAfrican Academy of Christian Surgeons (PAACS) 
and other mission hospital staff, has offered opportunities for research and development projects across regions. One example is a recent article on improving diagnosis and treatment of chromoblastomycosis in rural Madagascar. ${ }^{23}$

Engaging 2-4 health professionals-in-training (medical/dental school or residency) as academic assistants at conferences has not only improved the flow of conference activities, but has also presented an opportunity for young professionals interested in global health and ministry to see firsthand the complexity and reality of international healthcare, as well as consider opportunities to support this work by doing research or developing as international healthcare educators, as demonstrated by the following quote:

\section{Serving as an academic assistant provided me the opportunity to interact with international healthcare workers in genuine ways beyond the glow that often comes with serving abroad to see the ordinary challenges and heartening opportunities of providing competent and compassionate care in a cross-cultural setting. As a healthcare professional still in training, I also appreciated seeing the authentic contributions of academic and clinical educators towards strengthening the global safety net.}

The diverse gathering of faculty, staff, volunteers, and participants at each year's conference provides mutual inspiration and encouragement, affirming the mission of the program to advance God's kingdom from whichever vocational setting to which we are called. Through both quantitative and qualitative presentation, this paper describes a unique program that both supports the work of international healthcare workers and develops international healthcare educators.

\section{References}

1. Campbell E. Medical mission work. In: Evangelical Dictionary of World Missions. Grand Rapids, MI: Baker Academic; 2000.

2. Price FW, March AW. Protestant medical missions today. Occasional Bulletin. 1959;10(03):1-10.

3. Loewenberg S. Medical missionaries deliver faith and health care in Africa. The Lancet. 2009;373(9666):795-6. http://dx.doi.org/10.1016/S0140-6736(09)60462-1

4. Grundmann CH. The Contribution of medical missions: the intercultural transfer of standards and values. Academ Med. 1991;66(12):731-3. http://dx.doi.org/10.1097/00001888-199112000-00005

5. Easterly W. The white man's burden: how the West's efforts to aid the rest have done so much ill and so little good. NY: Penguin Books. 2006.

6. Maurice J. Faith-based organisations bolster health care in Rwanda. . The Lancet. 386(9989):123-124. http://dx.doi.org/10.1016/S0140-6736(15)61213-2

7. Koteskey R. Attrition. CMDA Epistle. 2015.

8. Taylor WD. Revisiting a provocative theme: the attrition of longer-term missionaries. Missiology: An Int Rev. 2002;30(1):67-80.

9. Grundmann CH. Sent to heal! Emergence and development of medical missions. Lanham, MD: University Press of America. 2005.

10. Bikos L, Lewis Hall E. Psychological functioning of international missionaries: introducion to the special issue. Ment Heal Relig Cul. 2009;12(7):605-609. http://dx.doi.org/10.1080/13674670903312427

11. Eriksson C, Bjorck J, Larson L, et al. Social support, organisational support, and religious support in relation to burnout in expatriate humanitarian aid workers. Ment Heal Relig Cult. 2009;12(7):671-86. http://dx.doi.org/10.1080/13674670903029146

12. Grundmann C. The contribution of medical missions to medical education overseas. Mission Studies. 
1992;9(17):79-99.

http://dx.doi.org/10.1163/157338392X00072

13. Foyle M, Watson J. Expatriate mental health. Actu Psychiatr Scand. 1998;97:278-83. http://dx.doi.org/10.1111/j.1600-0447.1998.tb10000.x

14. Koteskey R. Psychology for missionaries. Wilmore, KY: GO International. 2011.

15. Hawley D. Research on missionary kids and families: a critical review. Missions Resour Netw. 2004:1-13.

16. Strand M, Pinkston L, Chen A, Richardson JW.. Mental health of cross-cultural healthcare missionaries. J Psychol Theol. 2015;43(4):283-93.

17. Strand M, Cole A. Framing the role of the faith community in global health. Christ J Glob Heal. 2014;1(2):7-15. http://dx.doi.org/10.15566/cjgh.v1i2.19

18. Strand MA, Chen AI, Pinkston LM. Developing cross-cultural healthcare workers: content, process, and mentoring. Christ J Glob Heal. 2016;3(1):57-72. http://dx.doi.org/10.15566/cjgh.v3i1.102
19. CMDA. About us [Internet]. Available from: https://cmda.org/about/ [Cited 2016 Aug 9]

20. Strand M, Mellinger J, Slusher T, Chen A, Pelletier A. Re-imaging medical missions: results of the PRISM Survey. Evangel Missiol Quart. 2013;49(4):430-9.

21. Strand MA. Report of the PRISM Survey: patterns and responses in intercultural service in medicine. [Research Report]. Medical Missions Survey Working Group of the CMDA. 2011.

22. Strand MA, Paulson E, Myrick T. Characterizing the global context for cross-cultural healthcare work by regions of the world. Christ J Glob Heal. 2015;2(2):2338. http://dx.doi.org/10.15566/cjgh.v2i2.78

23. Santmyire A. The Effectiveness of a multifocal training to improve the treatment of chromoblastomycosis in rural Madagascar. J Health Care Poor U. 2016; 27:993-1010.

http://dx.doi.org/10.1353/hpu.2016.0146

Peer Reviewed

Competing Interests: None declared.

Correspondence: Lyubov D Slashcheva, University of Department of Preventive and Community Dentistry, lowa, United States. Iyubov-slashcheva@uiowa.edu

Cite this article as: Slashcheva LD, Strand MA, VanReken RE, Sanford C, Phillips JD, Halverson G. Continuing medical and dental education on the global stage: the nexus of supporting international Christian healthcare workers and developing educators. Christian Journal for Global Health (Nov 2016), 3(2):27-37.

(C) Slashcheva LD, Strand MA, VanReken RE, Sanford C, Phillips JD, Halverson G This is an open-access article distributed under the terms of the Creative Commons Attribution License, which permits unrestricted use, distribution, and reproduction in any medium, provided the original author and source are properly cited. To view a copy of the license, visit http://creativecommons.org/licenses/by/4.0/

WWW.cjgh.org

Nov 2016. Christian Journal for Global Health, 3(2): 27-37. 